\title{
A High Efficiency, Kinetic-Ejection Negative Ion Source for RIB Generation
}

\author{
G. D. Alton, Y. Liu, C. Williams and S. N. Murray \\ Physics Division, Oak Ridge National Laboratory, P. O. Box 2008, Oak Ridge, TN 37831-6368 USA \\ MAR $O 31999$ \\ 0 std
}

\begin{abstract}
Chemically active radioactive species, diffused from RIB target materials, often arrive at the ionization chamber of the source in a variety of molecular forms. Because of the low probability for simultaneously dissociating and efficiently ionizing the individual atomic constituents of molecules with conventional hot-cathode electron-impact ion sources, the species of interest are often distributed in several mass channels in the form of molecular side-band beams and consequently, their intensities are diluted. The sputter negative ion beam generation technique offers an efficient means for simultaneously dissociating and ionizing highly electronegative atomic species present in molecular carriers. We have incorporated these principles in the design and fabrication of a kinetic ejection negative ion source and evaluated its potential for generating ${ }^{17,18} \mathrm{~F}^{-}$beams for the Holifield Radioactive Ion Beam Facility astrophysics research program. The source utilizes $\mathrm{Cs}^{+}$beams to bombard condensable fluorine compounds that emanate from a target material, such as $\mathrm{Al}_{2} \mathrm{O}_{3}$, and are transported to the cooled inner surface of a conical-geometry cathode where they are adsorbed. The energetic $\mathrm{Cs}^{+}$beams efficiently dissociate these molecules and sputter their constituents. Since the work functions of cesiated surfaces are low, highly electronegative species such as fluorine are efficiently ionized in the sputter-injection process. Measured efficiencies for ionizing atomic fluorine, dissociated from condensable compounds that are formed by reactions of $\mathrm{SF}_{6}$ with fibrous $\mathrm{Al}_{2} \mathrm{O}_{3}$ material, exceed $6.5 \%$. In this report, we describe the mechanical design features and principles of operation, and present emittance, $\mathrm{F}^{-}$ yield and ionization efficiency data derived from off-line, experimental evaluation of the source.
\end{abstract}

\section{INTRODUCTION}

Production of radioactive species at the HRIBF [1] is effected by directing beams of either $10-60 \mathrm{MeV}$ protons/deuterons, or $10-100 \mathrm{MeV}{ }^{3} \mathrm{He} /{ }^{4} \mathrm{He}$ from the Oak Ridge Isochronous Cyclotron (ORIC) onto refractory target material maintained at high temperature and close-coupled to an ion source. Because the HRIBF relies on the 25 MV tandem electrostatic accelerator for propelling beams to research energies, negative ion beams must be injected into the device. With the exception of the noble-gas elements ( $\mathrm{Ne}, \mathrm{Ar}, \mathrm{Kr}$ and $\mathrm{Xe}$ ), most chemically active RIB species can be formed as atomic or molecular ions by utilization of either the sputter or charge-exchange negative ion generation processes. The charge-exchange process relies on sequential electron 


\section{DISCLAIMER}

This report was prepared as an account of work sponsored by an agency of the United States Government. Neither the United States Government nor any agency thereof, nor any of their employees, make any warranty, express or implied, or assumes any legal liability or responsibility for the accuracy, completeness, or usefulness of any information, apparatus, product, or process disclosed, or represents that its use would not infringe privately owned rights. Reference herein to any specific commercial product, process, or service by trade name, trademark, manufacturer, or otherwise does not necessarily constitute or imply its endorsement, recommendation, or favoring by the United States Government or any agency thereof. The views and opinions of authors expressed herein do not necessarily state or reflect those of the United States Government or any agency thereof. 


\section{DISCLAIMER}

Portions of this document may be illegible in electronic image products. Images are produced from the best available original document. 
transfer interactions between an initially positive-ion beam and a suitably chosen exchange vapor to form the negative-ion beam. As a consequence, the over-all efficiency is often low due to the product of probabilities for first forming the positive ion beam that then must be converted to negative polarity. In addition, the chargeexchange process degrades the quality of beams (emittances) because of its collisional nature.

${ }^{17,18} \mathrm{~F}$ beams are of considerable interest for astrophysics research because they play important roles in the hot $\mathrm{CNO}$ cycles and rp-processes responsible for heavy element synthesis in the universe. While it is easy to generate intense beams of stable $\mathrm{F}^{-}$in sputter-type negative ion sources conventionally used at tandem based facilities, the generation of adequate intensities of ${ }^{17} \mathrm{~F}^{-}$for $\mathrm{RIB}$ applications has proved to be especially difficult because of the sequential times required for diffusion of the isotope from the interior of the target material and effusive flow to the ion source in relation to its lifetime $\left(\tau_{1 / 2}: 65 \mathrm{~s}\right)$. The times required for each of these processes strongly depend on the chemical reactivity of the species with the target material and with the materials of construction of the vapor transport system as well as the geometry and operational temperature of the target/ion source system. In general, these delay times must be reduced to values commensurate with the lifetime of the particular RIB species in order to provide adequate intensities for RIB research.

Chemically active radioactive species, such as $\mathrm{F}$, more often than not, arrive at the ionization chamber of the source in a variety of molecular forms. Because of the low probability for simultaneously dissociating and efficiently ionizing atomic constituents of molecules containing the element of interest by use of conventional hot-cathode electron-impact ion sources, the desired species are often distributed in several mass channels in the form of molecular side-band beams and consequently, the RIB intensity is diluted. This effect is illustrated in Fig. 1 which shows the mass distribution of fluorine-rich ion beams extracted from the electron beam plasma ion source (EBPIS) (2) used for positive ion beam generation at the HRIBF. The beams were formed from compounds synthesized in chemical reactions between $\mathrm{SF}_{6}$

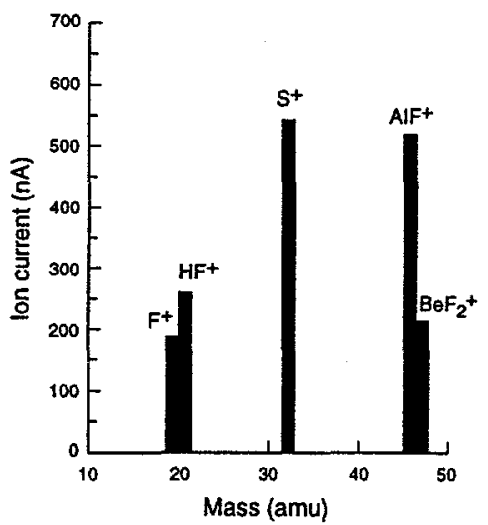

Fig. 1. Magnetic analysis mass spectrum for beams extracted from the EBPIS (2) illustrating that the source is ineffective for simultaneously dissociating and ionizing the constituents of fluorine-rich compounds. Note that only $13 \%$ of the atomic ${ }^{19} \mathrm{~F}$ appears in the 19 mass-channel. and fibrous $\mathrm{Al}_{2} \mathrm{O}_{3}$ target material under identical conditions to those used to test the source described in this article. As noted, only $13 \%$ of the ${ }^{19} \mathrm{~F}$ species appear in the atomic mass-channel. Since the $\mathrm{F}^{+}$must be subjected to charge-exchange conversion to form $\mathrm{F}^{-}$, the overall efficiency of the process is $<0.06 \%$ at $10 \%$ charge-exchange efficiency.

The sputter negative ion beam generation technique is a particularly effective means for 
simultaneously dissociating molecular carriers and efficiently ionizing highly electronegative atomic constituents present in the molecule. For these reasons, we have conceived, designed, fabricated and extensively evaluated an efficient kinetic-ejection negative-ion source for the direct generation of ${ }^{17} \mathrm{~F}^{-}$and ${ }^{18} \mathrm{~F}^{-}$beams for potential use in the astrophysics research program at the HRIBF. The sputter generation technique also overcomes the rather severe and chronic poisoning effects incumbent with sources equipped with conventional thermal-evaporation-type LaB6 surface ionizers (3). In this article, we describe the mechanical design features, principles of operation and optics of the source, and provide operational parameter, emittance, and efficiency data for the generation of $\mathrm{F}^{-}$.

\section{DESCRIPTION OF THE SOURCE}

\section{Design features}

The design features of the kinetic ejection source are illustrated schematically in Figs. 2 and 3. The source is designed to mount in the same vacuum housing used for positive sources such as the electron-beam-plasma source (EPBIS), routinely used at the HRIBF for RIB generation (2). The source consists of a Re-lined Ta target-material reservoir transversely attached to a Re-lined, Ta vapor-transport tube that directs particles emanating from the target material reservoir toward the ionization chamber of the source. ( $R e$ is used as a liner, where practicable, to reduce the effusive flow times

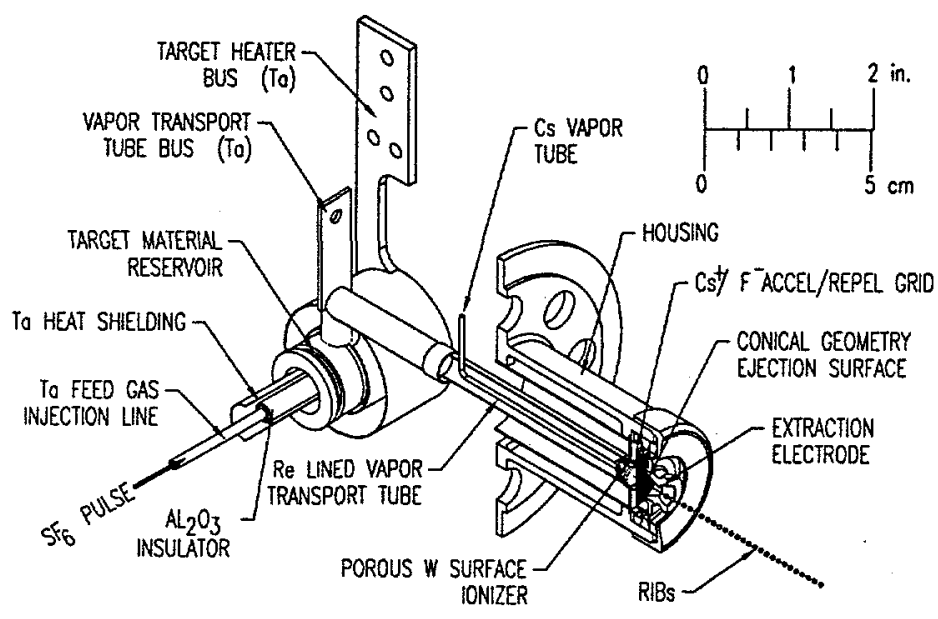

Fig. 2. Isometric cut-away drawing of the kinetic ejection negative ion source designed for potential use at the HRIBF for radioactive ion beam generation.

from the target to the ionization region of the source because of its low enthalpy of adsorption properties for many elements.) The temperature of the target material is controlled by varying the current through a triple-pass, cylindrical $\mathrm{Ta}$ heater that coaxially surrounds the target material reservoir. The transport tube is independently heated by passing a current along the tube. Although the target material reservoir and the transport tube are mechanically attached, their temperatures can be independently controlled with little coupling. $\mathrm{SF}_{6}$ is injected at a precisely controlled rate into the target reservoir where it reacts with fibrous $\mathrm{Al}_{2} \mathrm{O}_{3}$ to form fluorine-rich compounds that are transported to the ionization region of the source. Cs vapor is 
transported from an externally controlled Cs-oven through an independent transport tube coaxially located within the vapor transport tube and weld attached to a $50 \%$ porosity $\mathrm{W}$ ionizer. Since the ionizer is welded to the exit end of the transport tube, changes in transport-tube heating power result in changes in the temperature of the ionizer. As is well known, the W-ionizer must be operated at temperatures above the critical temperature $\left(\sim 1100^{\circ} \mathrm{C}\right)$ for efficient surface ionization of

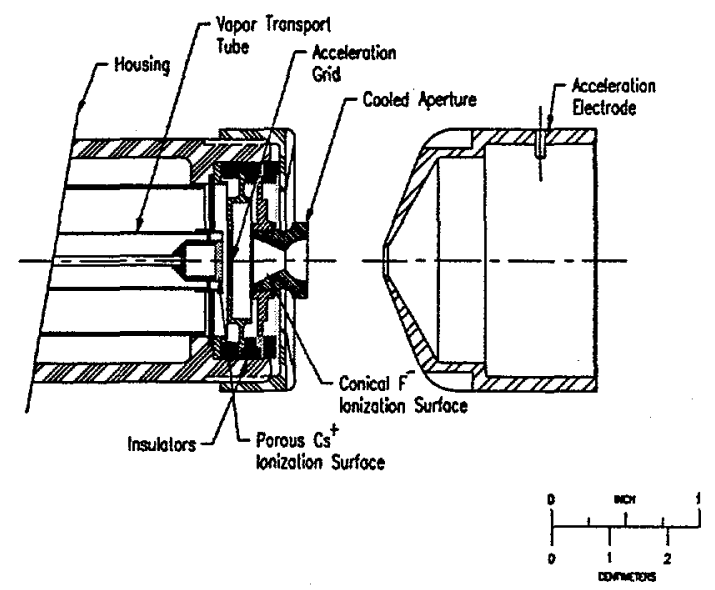

Fig. 3. Side-view of the negative ion formation reg ion of the kinetic ejection negative source showing the Cs-ionizer, the acceleration grid, and the conical-geometry cathode.

$\mathrm{Cs}^{\circ}$ (4). Therefore, it was necessary to design the integrated system so that the optimum ionizer and transport-tube temperatures could be simultaneously achieved by adjusting the current through the transport tube.

\section{Principles of operation}

The species of interest, emanating from the target material in vapor form, exit the vapor transport tube through an annular aperture surrounding the W-ionizer where they strike the surface of the conical-geometry cathode equipped with provisions for gas $/ \mathrm{H}_{2} \mathrm{O}$ or liquid nitrogen cooling for condensing or perhaps, trapping molecules. However, the effects of cooling the cathode on the ionization efficiencies were not measured during these investigations. Such studies will be emphasized in a future paper. $\mathrm{Cs}^{+}$ions, formed by surface ionization are accelerated through a negativelybiased, $~ 90 \%$-transparency, Mo-grid, maintained at voltages up to $-300 \mathrm{~V}$ where they impact the inner surface of the cathode and kinetically eject particles from the surface. The $\mathrm{Cs}^{+}$beam, in combination with neutral $\mathrm{Cs}^{0}$ vapor, lowers the work function (5), dissociates carrier molecules and kinetically ejects their constituents. The mechanism responsible for negative ion formation is well understood (6) and is rather efficient for many atoms/molecules with intermediate to high electron affinities. Moreover, it does not rely on thermal evaporation of the species of interest to effect ionization as does conventional surface ionization. Thus, the adsorption surface can be operated at low temperatures for volatile molecules, thereby increasing their residence times and consequently the probability for dissociation and ionizing their constituents. In cases where the species of interest has a high electron affinity, but is an constituent of a carrier molecule that has a low or even negative electron affinity, as is the case for $F$ in $\mathrm{AlF}$, and cannot themselves be efficiently formed as negatively ions, it is quintessential to be able to dissociate the carrier molecule in order to ionize the species of interest and concentrate them into a single mass-channel. 


\section{$\mathrm{Cs}^{+}$and $\mathrm{F}^{-}$beam optics}

The electrode systems for the acceleration of $\mathrm{Cs}^{+}$and extraction of $\mathrm{F}^{-}$were computationally designed by the use of the simulation code PBGuns (7). The $\mathrm{Cs}^{+}$ electrode system was designed to have a high perveance for $\mathrm{Cs}^{+}$beams while efficiently extracting negative ions formed on the conical surface during the sputter process. The space charge limited current flow between two parallel electrodes is given by the familiar Childs-Langmuir relation

$$
I(m A)=1 \times 10^{3}\left\{(4 / 9) \varepsilon_{0}(2 e / M)^{I / 2} A / d^{2}\right\} V^{3 / 2}
$$

where $\varepsilon_{o}$ is the permitivity of free space, $e$ is the charge on the electron, $M$ is the mass of Cs, $A$ is the area of the ionizer and $d$ the spacing between the grid and the ionizer surface. The calculated perveance for the planar geometry ionizer grid electrode system with spacing $1 \mathrm{~mm}$ is: $\mathrm{P}=1.5 \times 10^{-7}\left[\mathrm{~A} / \mathrm{V}^{3 / 2}\right]$. This correlates to space charge limited $\mathrm{Cs}^{+}$beams, respectively, of $424 \mu \mathrm{A}$ at a grid voltage of $-200 \mathrm{~V}$ and $779 \mu \mathrm{A}$ at a grid voltage of $-300 \mathrm{~V}$.

The optics of the system were designed to assure uniform irradiation of the surface of the conical geometry cathode with $\mathrm{Cs}^{+}$beam intensities sufficiently high to ensure optimum probability for dissociating adsorbed fluorine-rich molecules and negatively ionizing their atomic fluorine constituents. $\mathrm{Cs}^{+}$beam trajectories accelerated through the gridded electrode and onto the conical geometry cathode are illustrated in Fig. 4.

Analogously, the negative ion optics were designed to optimize

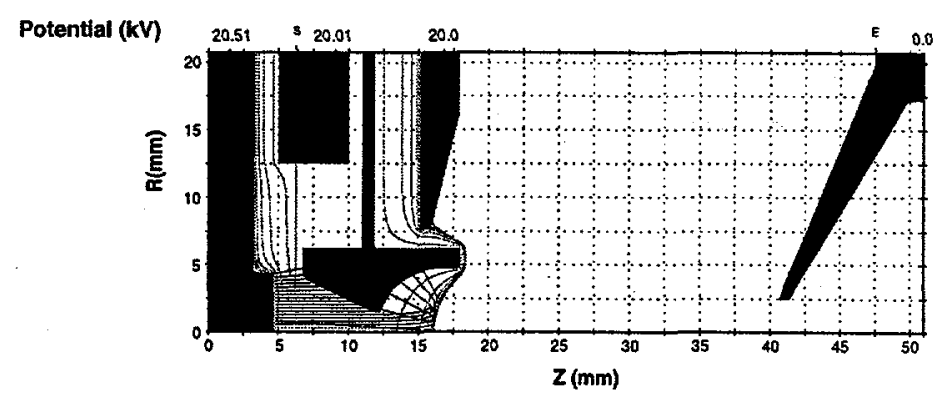

Fig. 4. Simulation of the $\mathrm{Cs}^{+}$beam optics from the W-ionizer surface through the negatively biased acceleration grid and onto the conicalgeometry cathode where negative ions are kinetically ejected. The simulations were performed with PBGuns (7). extraction of sputter ejected $\mathrm{F}^{-}$. The results of these simulation studies are shown in Fig. 5. A grid voltage of at least $-10 \mathrm{~V}$ to $-20 \mathrm{~V}$, more negative than the potential of the conical geometry cathode was found to be necessary in order to optimize negative-ion extraction. The action of the low gradient field is to reflect negative ions that otherwise would drift toward the grid and be lost. Particles are extracted from the source through a 2-mm diameter aperture in the apex of the cone by the penetrating electrostatic field produced between the conical geometry cathode, maintained at $\sim-20.3 \mathrm{kV}$ potential relative to the ground potential extraction electrode. 


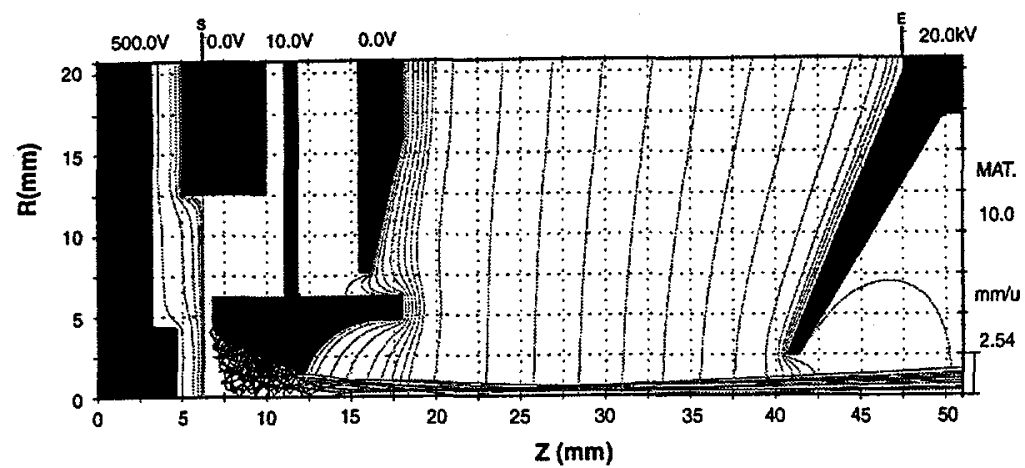

Fig. 5. Simulation of the $F^{-}$beam optics during ejection and extraction from the conical-geometry cathode surface. The grid-electrode is biased slightly more negative than the conical-geometry cathode to accelerate the $\mathrm{F}^{-}$beam toward the exit aperture. The simulations were performed with PBGuns (7).

\section{The $\mathrm{SF}_{6}$ feed system}

Fluorine-rich gases such as $\mathrm{CF}_{4}, \mathrm{CCl}_{2} \mathrm{~F}_{2}$ and $\mathrm{SF}_{6}$ are viable candidates for use as fluorinating agents in the system because they are chemically inert and thermally stable at low temperatures but decompose at elevated temperatures, releasing known amounts of $\mathrm{F}$ into the high-temperature ion-source. Of course, the thermal dissociation fractions of the molecule in relation to the temperature distribution within the source must be known. The thermal decomposition characteristics of molecules such as these can be calculated by use of thermo-chemistry codes such as HSC (8), ThermoCalc (9) and ChemSage (10). $\mathrm{SF}_{6}$ was chosen because of its high concentration of $\mathrm{F}$ and the ease at which it can be dissociated to release $\mathrm{F}$ and $\mathrm{F}_{2}$ gas for reaction with the $\mathrm{Al}_{2} \mathrm{O}_{3}$ fibrous target material used in testing the ionization efficiency of the source (11). In order to make a viable estimation of the efficiency of the ion source for on-line $\mathrm{F}^{-}$generation, it is quintessential to evaluate the source with compounds identical to those released during on-line operation. The computed equilibrium distributions of fluorine-rich compounds that result from the reaction of $\mathrm{SF}_{6}$ with $\mathrm{Al}_{2} \mathrm{O}_{3}$ at various temperatures (10) are shown in Fig. 6. At temperatures above $\sim 1400{ }^{\circ} \mathrm{C}$, the principal

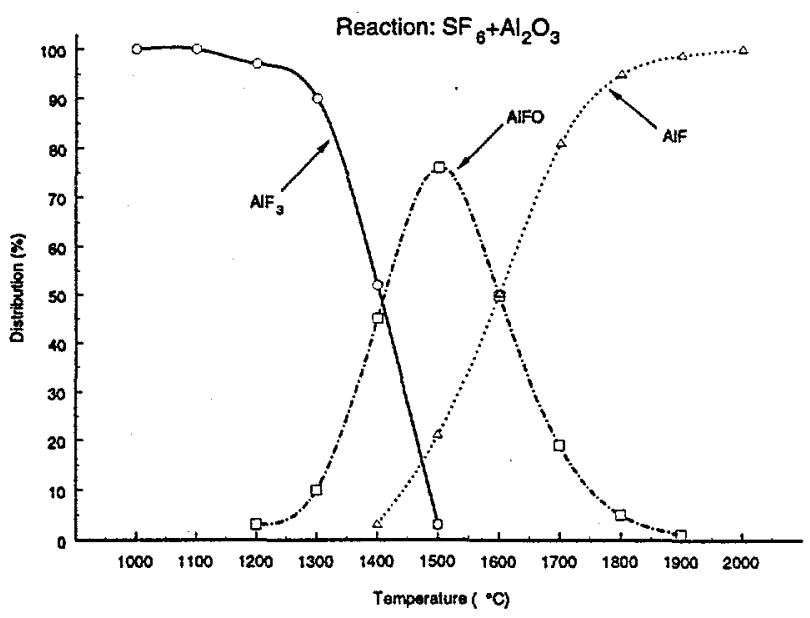
components are AlFO and AlF both of which are gaseous at Fig. 6. Equilibrium distributions of principal fluorine-rich temperatures above $\sim 253{ }^{\circ} \mathrm{C}$. compounds resulting from the interaction of $\mathrm{SF}_{6}$ with $\mathrm{Al}_{2} \mathrm{O}_{3}$, as calculated with ChemSage (10). 
(AlF has been confirmed as the principal carrier of fluorine during on-line operation of the EBPIS.)

The feed system for gases consists of a small stainless-steel chamber of known volume that is equipped with both capacitance manometer and Bourdon gauge pressure monitors. The chamber is filled with the chosen feed gas $\left(\mathrm{SF}_{6}\right)$ where it is pressure fed from the chamber into the source through a precision, calibrated-leak, also made of stainless steel, designed to introduce $\sim 3.6 \times 10^{13}$ atoms/s of Xe into the source at 1 bar pressure across the leak. Feed gas from the calibrated leak is introduced into the source in pulsed mode by opening and closing a mechanical gate-valve in series with the calibrated leak and the high-temperature ion source. The time dependence of the rise and fall of the negative ion beam intensity at opening/closing provides information on the delay-times for transport of the fluorine-rich compounds to the ionization region of the source. The transport tube, located between the mechanical valve and targetmaterial reservoir, is made of Ta; the feed gas injection end of the tube is equipped with a heat-sink avoid dissociation temperatures for the $\mathrm{SF}_{6}$ feed gas at entrance to the target material reservoir. $\left(\mathrm{SF}_{6}\right.$ begins to thermally dissociate at $\sim 650{ }^{\circ} \mathrm{C}$.) The interface connection between the gas feed tube and the target material reservoir is sealed with a close-fitting $\mathrm{Al}_{2} \mathrm{O}_{3}$ insulator to prevent leaks at the interface while providing thermal isolation of the tube.

\section{OPERATIONAL PARAMETERS}

In order to optimize the ionization efficiency of the source, it is necessary to know the dependencies of both $\mathrm{Cs}^{+}$and $\mathrm{F}^{-}$beam intensities on the important operational parameters of the source. The most important operational parameters include: negative ion beam intensity versus $\mathrm{Cs}^{0}$ oven temperature; negative ion-beam intensity versus ionizer temperature; and negative ion-beam intensity versus kinetic energy of the $\mathrm{Cs}^{+}$ beam. The $\mathrm{Cs}^{+}$beam intensity can be estimated from Eq. 1 or from power supply drain currents. Other parameters such as negative-ion beam intensity versus target material reservoir temperature, negative-ion beam intensity versus cone temperature and negative-ion beam intensity versus cone voltage are also very important but will not be presented in this article because of brevity considerations. A more detailed account of the source with all parameters given will be the subject of a forthcoming article. All of these parameters were carefully measured for the source. Once established, the source is extremely easy to operate with the power supply inputs for control of the Cs oven, ionizer and target material reservoir temperatures and voltages for the grid electrode and conical geometry cathode voltages usually fixed. The source operates very stably and reliably without the need for constant operator attention and, to date, has demonstrated a continuous operational lifetime exceeding one month.

\section{$F^{-}$beam intensity versus Cs oven temperature}

The probability for negative ion formation during sputtering depends exponentially on the difference between the electron affinity $E_{A}$ of the atom/molecule and the value of 
the work function $\phi$ of the surface (7); the work function, $\phi$, in turn, depends on the Cs coverage (5). The flow of Cs through the ionizer provide $\mathrm{Cs}^{+}$beams for bombarding the conical-geometry surface from which the atoms/molecules are sputtered as well as a neutral $\mathrm{Cs}^{\circ}$ flux for lowering the work function. Therefore, knowledge of the dependence of negative ion yield on Cs oven temperature is quintessential for optimum performance of the source. Figure 7 displays $\mathrm{F}^{-}$yield versus $\mathrm{Cs}$ oven temperature for the source. As noted the optimum temperature is $\sim 200^{\circ} \mathrm{C}$.

\section{$F^{-}$beam intensity versus ionizer temperature}

The W-ionizer temperature must be operated above the characteristic onset for positive ion formation, commonly referred to as the critical temperature (4). For $\mathrm{Cs}^{\circ}$ vapor incident on or passing through a hot $\mathrm{W}$ ionizer, this temperature is $\sim 1100{ }^{\circ} \mathrm{C}$. As noted in Fig. 8, the transport tube/Cs-ionizer can be operated over a rather wide range of temperatures without compromising the $\mathrm{F}^{-}$ beam intensity, thus simplifying source operation.

\section{Negative ion beam intensity versus $\mathrm{Cs}^{+}$beam energy}

Since the sputtering process is sensitively dependent on projectile energy in the low energy regime, it is crucially important to supply a $\mathrm{Cs}^{+}$ beam with sufficient intensity and energy so that the $\mathrm{F}^{-}$beams intensity versus ion energy reaches a constant value. As noted in Fig. 9, the negative ion beam intensity reaches saturation at

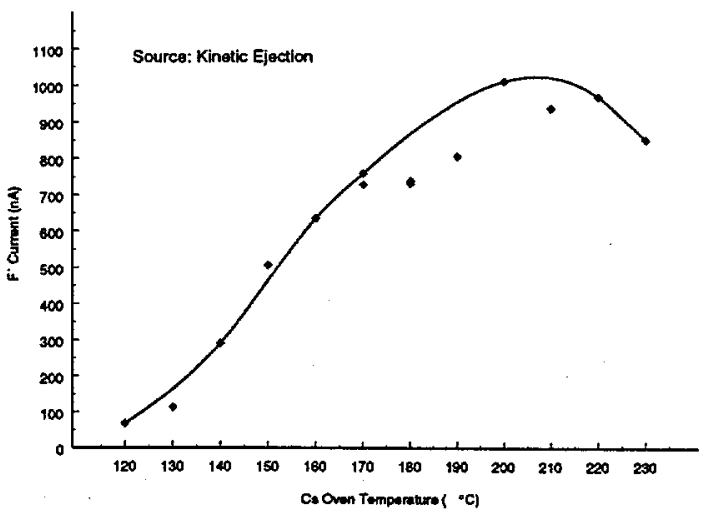

Fig. 7. $F^{*}$ beam intensity versus Cs-oven temperature for the kinetic ejection negative ion source.

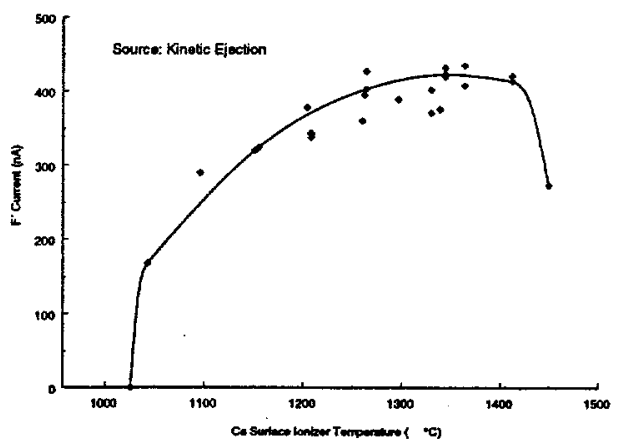

Fig. 8. $F^{-}$beam intensity versus W-surface ionizer temperature for the kinetic ejection negative ion source.

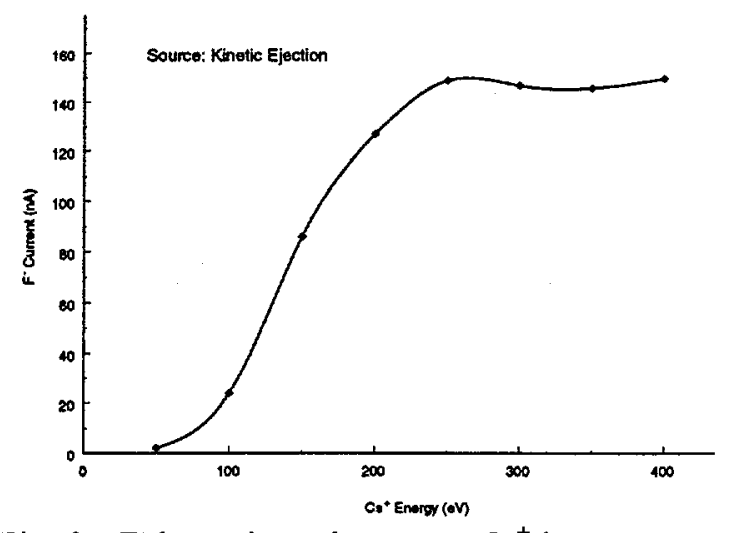

Fig. 9. $\mathrm{F}^{-}$beam intensity versus $\mathrm{Cs}^{+}$beam energy for the kinetic ejection negative ion source. 
$\sim 200 \mathrm{eV} \mathrm{Cs}^{+}$beam energy signifying that the intensity and kinetic energy of the $\mathrm{Cs}^{+}$ beam is adequate for dissociating and sputtering the constituents of fluorine compounds.

\section{SOURCE PERFORMANCE AND BEAM QUALITY CHARACTERISTICS}

\section{$F^{0}$ ionization efficiency measurements}

In on-line experiments at the HRIBF, ${ }^{17,18} \mathrm{~F}$ are produced within the volumes of refractory oxide targets through fusion-evaporation reactions such as ${ }^{16} \mathrm{O}(\mathrm{d}, \mathrm{n}){ }^{17} \mathrm{~F}$ or ${ }^{18} \mathrm{O}(\mathrm{p}, \mathrm{n}){ }^{18} \mathrm{~F}$. Because of the relatively short half-life of ${ }^{17} \mathrm{~F}\left(\tau_{1 / 2}: 65 \mathrm{~s}\right)$, the diffusion and effusive flow path lengths must be kept as short as practical. Fortunately, several oxides $\left(\mathrm{Al}_{2} \mathrm{O}_{3}, \mathrm{Y}_{2} \mathrm{O}_{3}, \mathrm{ZrO}_{2}, \mathrm{SiO}_{2}, \mathrm{Ta}_{2} \mathrm{O}_{5}, \mathrm{Hf}_{2} \mathrm{O}_{3}\right)$, can be formed into highly permeable woven mats made of long, thin fibers (2-10 $\mu \mathrm{m}$ diameter) which combine the short diffusion length/high permeability (low density) characteristics required of ISOL targets for efficient diffusion release and effusive flow transport to the ion source (11). The most likely release products will be in the form of oxy-fluorides or metal mono-fluorides. In on-line tests, conducted at the HRIBF, fibrous $\mathrm{Al}_{2} \mathrm{O}_{3}$ has been used for the production and efficient release of ${ }^{17,18} \mathrm{~F}(12)$ and, therefore, was used as the target material during testing of the source. Other more refractory oxides (such as $\mathrm{ZrO}_{2}$ and $\mathrm{HfO}_{2}$ ) are presently under evaluation for ${ }^{17,18} \mathrm{~F}$ generation, as well. As noted in Fig. 6, the principal carrier of $\mathrm{F}$ from $\mathrm{Al}_{2} \mathrm{O}_{3}$ will be $\mathrm{AlOF}$ and $\mathrm{AlF}$ whenever the target is operated within the temperature range of $1500{ }^{\circ} \mathrm{C}-1700^{\circ} \mathrm{C}$. Moreover, they are gaseous at temperatures above $-253{ }^{\circ} \mathrm{C}$.

Furthermore, once formed, AlF does not react appreciably with $\mathrm{Cs}^{\circ}$ over a broad range of temperatures used for routine operation of the source nor does it react with $\mathrm{H}_{2}$ used as a reagent for picking up elemental $\mathrm{F}$ from metal surfaces and efficiently transporting the product, $\mathrm{HF}$, to the ionization region of the source. However, both $F$ and $F_{2}$ readily react with $\mathrm{H}_{2}$ or $\mathrm{Cs}^{\circ}$ to form, respectively, $\mathrm{HF}$ or $\mathrm{CsF}$, both of which are thermally stable up to $\sim 1650{ }^{\circ} \mathrm{C}$.

Figure 10 displays efficiency versus time for forming $\mathrm{F}^{-}$during the fluorination of $\mathrm{Al}_{2} \mathrm{O}_{3}$ and transport of fluorine-rich compounds to the conical geometry sputter surface. The data are

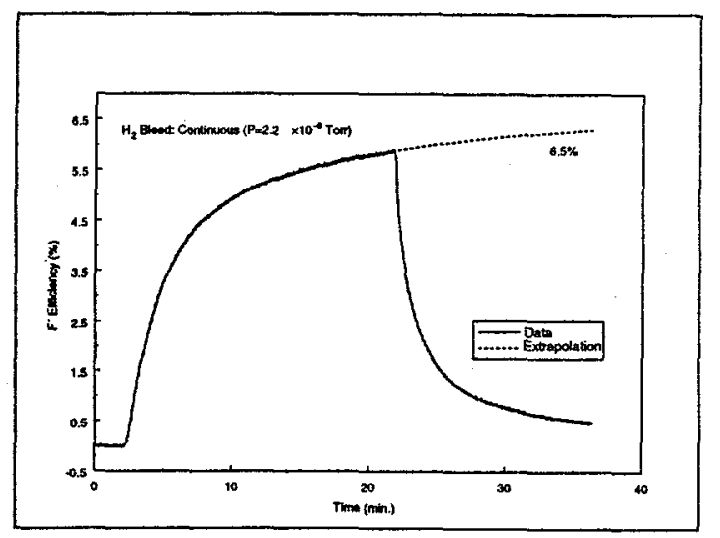

Fig. 10. Efficiency for forming $\mathrm{F}^{-}$versus target reservoir temperature for the kinetic ejection negative ion source. The data were taken without coolant on the conical geometry cathode. 
typical of those derived from the source after outgassing and reaching operational temperatures. The data were taken by injecting a long pulse of $\mathrm{SF}_{6}$ into the target material reservoir where it reacted with fibrous $\mathrm{Al}_{2} \mathrm{O}_{3}$ target material with a continuous bleed of $\mathrm{H}_{2}$ into the source. While $\mathrm{H}_{2}$ was found to reduce effusive flow times by $\sim 5$, the result of these studies show that it does not affect the ionization efficiency of the source. As noted, the efficiency reaches $6.5 \%$, a respectably high value considering the fact that the signal is derived from molecular dissociation of a variety of fluorine-rich compounds. The value is even more impressive when one considers that no coolant was used on the cathode. By its addition, the efficiency of the source is expected to increase to even higher values. This study will be reserved for a future and more comprehensive article on the source.

The efficiency for $\mathrm{F}^{-}$formation is found to decrease rather abruptly at target temperatures above $1400{ }^{\circ} \mathrm{C}$, approaching those for on-line operation. An example of this behavior is shown in

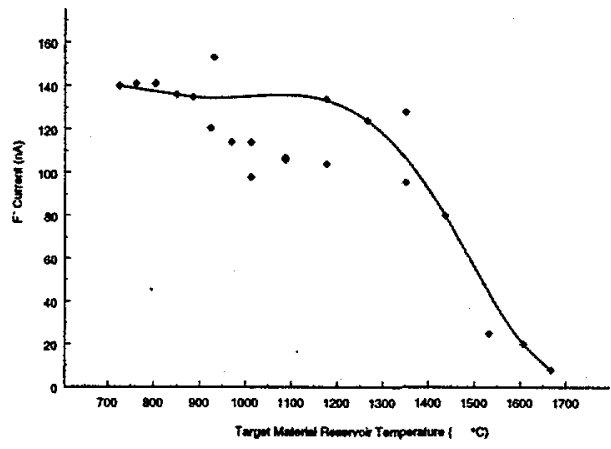

Fig. 11. Efficiency for $\mathrm{F}^{-}$formation versus target material reservoir temperature for the kinetic ejection negative ion source. Equivalent flow rate of $\mathrm{SF}_{6}$ into the source: $5.1 \mu \mathrm{A}$. Fig. 11. Although the origin of the decrease in efficiency is still not known, equilibrium distributions for $\mathrm{SF}_{6}$ interacting with $\mathrm{Al}_{2} \mathrm{O}_{3}$ fibrous target material, as shown in Fig. 6, suggest that the decrease may be attributable to changes in composition of the compounds with temperature or possibly to high pressures in the extraction region of the source.

\section{Mass Spectra}

The mass spectrum obtained by magnetic analysis of beams from the source is displayed in Fig. 12. As noted, the spectrum is simple with essentially $100 \%$ of the $\mathrm{F}^{-}$in the mass- 19 channel, in contrast to the spectra (Fig. 1) extracted from its hot-cathode positive counterpart, the EBPIS, where, only $13 \%$ of the $\mathrm{F}^{+}$is found to reside in the mass19 channel. In both instances, the beams were formed, under identical conditions, from compounds, synthesized in chemical reactions between $\mathrm{SF}_{6}$ and fibrous $\mathrm{Al}_{2} \mathrm{O}_{3}$ target material.

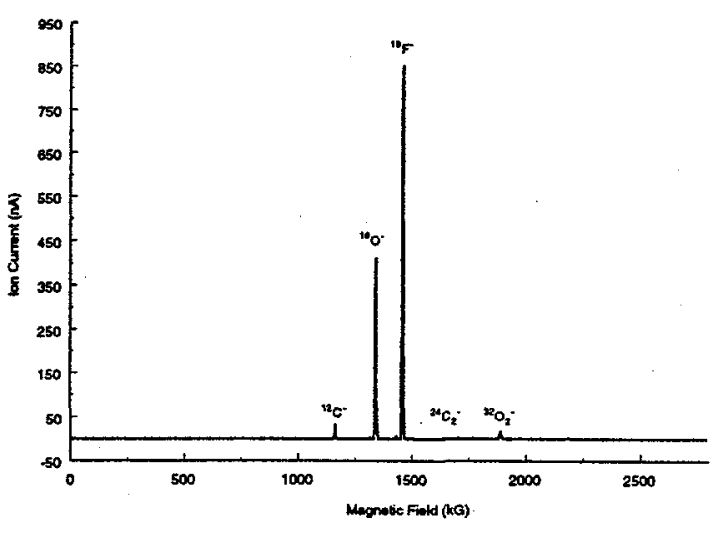

Fig. 12. Mass spectrum for the kinetic ejection source. Note that $100 \%$ of the ${ }^{19} \mathrm{~F}$ appears in the mass 19 channel This spectrum can be contrasted with that from the positive EBPIS, displayed in Fig. 1, where only $13 \%$ of the ${ }^{19} \mathrm{~F}$ appears in the 19 mass channel. 


\section{Emittance data}

Isobaric contamination problems are expected to be a serious problem during on-line ${ }^{17,18} \mathrm{~F}^{-}$beam generation because of the high electron affinity of oxygen $(1.46 \mathrm{eV})$ and its pervasiveness in the mass spectra of beams formed by the sputter process. This problem will be especially true when the targets are made of fibrous metal oxides. Therefore, the beam quality (emittance) of the beam is important because it affects mass resolution of these contaminants with existing magnetic analysis systems. The normalized emittance of the source is shown in Fig. 13 in comparison to that of the EBPIS. As noted, it is $\sim 2$ times larger than that of the EBPIS at the $80 \%$ contour level. The emittances of sputter generated negative ion beams are typically higher than positive produced by electron bombardment due to the inherently larger energy spread associated with the sputter process.

\section{ACKNOWLEDGEMENTS}

Research at the Oak Ridge National Laboratory is supported by the U.S. Department of Energy under contract DEAC05-96OR22464 with Lockheed Martin Energy Research Corp.

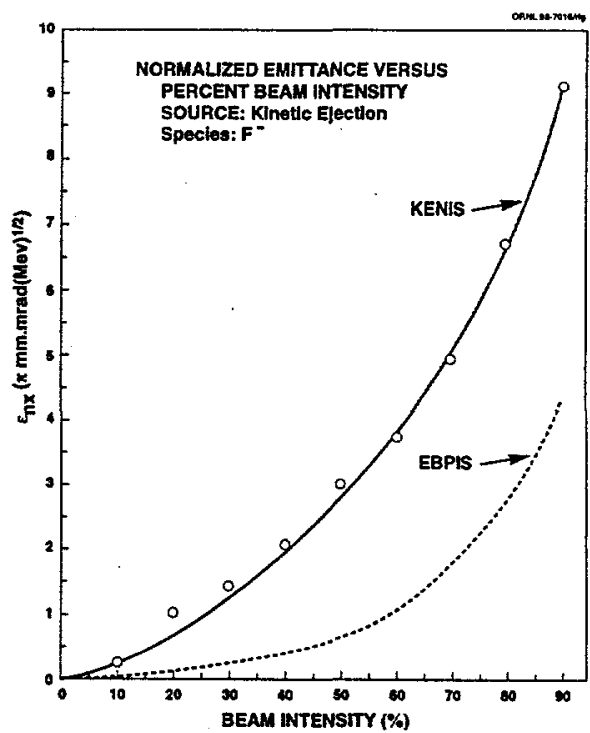

Fig. 13. Normalized emittance $\varepsilon_{\mathrm{n}}$ versus percentage of total beams for the kinetic ejection negative ion source.

\section{REFERENCES}

1. G. D. Alton and J. R. Beene, J. Phys. G: Nucl. Part. Phys. 24 (1998) 1347.

2. $\quad$ G. D. Alton, Rev. Sci. Instrum. 65 (1994) 1141

3. G. D. Alton, M. T. Johnson, Nucl. Instrum. and Meth. A 328 (1993) 154.

4. $\quad$ G. D. Alton, Rev. Sci. Instrum. 59 (1988) 1039.

5. G. D. Alton, Surf. Sci. 175 (1986) 226.

6. J. K. Nфrskov and B. I. Lundqvist, Phys. Rev. B 19 (1979) 5661.

7. PBGuns is a product of Thunderbird Simulations, Garland, Texas.

8. HSC is a chemical reaction and chemical equilibrium composition computer code and is a product of Outokumpu Research Oy, Pori, Finland

9. ThermoCalc is a chemical equilibrium composition and phase-diagram code developed by the Royal Institute of Technology, Stockholm, Sweden.

10. ChemSage is a chemical reaction and chemical equilibrium composition computer code and is a product of GTT Technologies, Herzogenrath, Germany

11. G. D. Alton, Application of Accelerators in Research and Industry, edited by, J. L. Duggan and I. L. Morgan, CP392, AIP Press, New York, 1997, 429.

12. D. Stracener, H. K. Carter, J. B. Breitenbach, J. Kormicki, J. C. Blackburn, M. S. Smith, and D. W. Bardayan, Application of Accelerators in Research and Industry, edited by, J. L. Duggan and I. L. Morgan, CP392, AIP Press, New York, 1997, 393. 